\title{
Hermenéutica del discurso fragmentario en Walter Benjamin
}

\section{(Hermeneutic interpretation of the fragmentary discourse in Walter Benjamin)}

\author{
Lluís Ballester Brage y Antoni J. Colom Cañellas
}

Recibido: 18 de febrero de 2013

Aceptado: 21 de mayo de 2013

\section{Resumen}

Este artículo propone una lectura hermenéutica del discurso fragmentario de uno de los autores de referencia de la teoría crítica. Se desarrolla el análisis a partir de la teoría de la traducción incompleta de Benjamin. Su estilo de escritura y sus tesis en constante proceso de revisión, se pueden entender como precursoras del deconstruccionismo. Esta posición especial de Benjamin no es fruto del azar, sino que es el producto de una determinada manera de entender la construcción de la teoría crítica.

Palabras clave: hermenéutica, discurso fragmentario, traducción incompleta, lenguaje, deconstrucción, teoría crítica.

\begin{abstract}
This paper proposes an hermeneutic interpretation of the fragmentary discourse of one of the authors of reference of the critical theory. The analysis develops from the theory of the incomplete translation of Benjamin. The Benjamin style of writing and its thesis in constant review process can be understood as precursors of the deconstruction. Our hypothesis is that this special Benjamin position is not developed by chance, but it is the result of a specific way of understanding the construction of the critical theory.
\end{abstract}

Keywords: hermeneutic, fragmentary discourse, incomplete translation, language, deconstruction, critical theory. 


\section{El discurso de Benjamin}

En este artículo se plantea el problema de la naturaleza excéntrica del discurso de Benjamin. Se ha escrito bastante sobre este tema por la sencilla razón de que forma y fondo, estilo y contenido son inseparables de la filosofía de Benjamin. Si esta idea nos resulta familiar es porque estamos acostumbrados a hablar así de los textos literarios. Pero no afirmamos con esto que la obra de Benjamin sea prosa literaria en lugar de filosofía, lo que planteamos es que su filosofía tiene calidades literarias, como la de Nietzsche u Ortega. El motivo literario penetra la filosofía que pretende llegar a un público amplio.

¿Walter Benjamin en el siglo XXI? Podemos hacer la pregunta en presente porque su obra lo mantiene entre nosotros como un contemporáneo más. Nos interesa y nos intriga, hace aportaciones y nos reclama esfuerzos para la comprensión de su pensamiento. Cuando se consigue entenderlo es porque nos entendemos mejor a nosotros mismos y a nuestro tiempo. Walter Benjamin es uno de los grandes autores de la cultura occidental europea en los años veinte y treinta del siglo XX; un inquieto crítico de esa cultura y de la sociedad en la que se desarrolla. Es uno de los pocos intelectuales completamente independientes del pensamiento europeo moderno, pero lo es de un modo particular que intentaremos analizar.

La estrategia de análisis que seguimos aquí consiste en plantear seis tópicos interpretativos y contestarlos a la luz de la obra de Benjamin:

- Sistema y fragmento. Los libros como obra abierta.

- El lenguaje (las múltiples lenguas) como lo auténticamente humano.

- El lector y las lecturas múltiples.

- Obra abierta y diferencia.

- Traducción imposible: comprensión y expresión limitadas.

- Diferencia insalvable o voluntad de comunicación.

Se trata de seis tópicos que se relacionan discursivamente, la tentativa de respuesta a cada uno de ellos ayuda a explicar al respuesta dada a los otros.

\section{Sistema y fragmento. Los libros como obra abierta}

Benjamin no completa con facilidad sus textos en el formato de libros convencionales. Esta constatación es aun más sorprendente en la tradición alemana de la filosofía, en la cual se encuentran muchos de los libros de referencia del pensamiento universal. El libro ha promovido la conservación y la diseminación de la sabiduría en todas las sociedades cultas. Es evidente que hay una distancia enorme entre 
las diversas concepciones de lo que es un libro, se puede destacar la materialidad del libro a expensas de su contenido; se puede hablar de la intencionalidad cultural más compleja que constituye la auténtica esencia del libro. La Biblia -el paradigma de la fascinación que el libro puede ejercer sobre un lector- no intentaba comunicar datos para distraer o divertir, sino que quiso dar entrada a las verdades más profundas sobre la existencia humana. De la misma manera, la tradición filosófica del mundo occidental ha querido transmitir de una generación a otra visiones del destino del ser humano y de todo el universo.

Puesto que el libro tiene el prodigioso poder de preservar, en forma material y con una entidad diferenciada, lo que antes sólo se podía conservar mediante la frágil memoria humana, ha ido ocupando a lo largo de la historia un lugar sumamente curioso y sin precedentes en los sueños de la humanidad. Al fijar en forma material el pensamiento y los diversos saberes que todo el mundo reconocía como más importantes, el libro asumió la pretensión de reflejar, ni más ni menos, la estabilidad y el orden de la realidad misma. De ahí la importancia de la ordenación interna de cada libro y las diversas tradiciones de libros (unos libros que comentan a otros) que tiene el libro en el sentido convencional, el hecho de que tenga un principio, un desarrollo y un fin.

Estos detalles estructurales, de cada libro y de cada tradición marcada por series de libros, este requisito de que un libro no literario ofrezca respuestas -en el sentido no sólo literal, sino también metafórico de la palabra 1 - nos revela algo esencial sobre las aspiraciones más profundas del ser humano. Así, implícitamente, el libro vino a ser una poderosa expresión del logos -sagrado o secular-que supuestamente existía tanto en el ser humano como en el universo. Históricamente, la valiosa experiencia del libro es incomprensible sin este presupuesto no necesariamente consciente, pero sí omnipresente.

Los textos de Benjamin no se corresponden con esta concepción convencional del libro. Si se busca en la obra de Benjamin una visión más o menos completa del conocimiento humano, si perseguimos un sistema o una fuerte coherencia interna, que lo unifique todo, no la vamos a encontrar. Si nos empeñamos en encontrar en los textos de Benjamin un orden y estabilidad conceptual, inevitablemente quedaremos decepcionados. Pero esta desilusión ha sido la experiencia de muchos lectores que aun así siguen admirando y aprendiendo de estos escritos. Son textos que interpelan a sus lectores. Se han identificado sus obras como ensayos o fragmentos en lugar de enfocarlas como libros sistemáticos y acabados. El género de comentario crítico que Benjamin cultiva es diferente tanto en su forma como en los efectos que produce. Por ejemplo, las citas o los textos críticos breves son técnicas expresivas que frecuenta. Es decir, utiliza claramente procedimientos intertextuales para provocar e iluminar.

\footnotetext{
${ }^{1}$ No es necesario conocer las preguntas ni habérselas planteado nunca.
} 
Benjamin prefería sugerir sus aportaciones en lugar de definirlas y elaborarlas en forma rigurosamente lógica; dejó apuntes inéditos, obras incompletas o en proceso, publicó reconstrucciones de apuntes circunstanciales. A la luz de todo esto, se puede concluir que no estamos hablando de libros en un sentido riguroso, sino de ensayos, notas de trabajo en proceso. Se puede destacar, solo en este sentido, un cierto paralelismo con Wittgenstein, en quien también se puede hallar una gran cantidad de material en elaboración permanente.

Una y otra vez, Benjamin despierta la curiosidad del lector, invitándole a participar en un movimiento hacia algo que parece una conclusión; pero pronto abandona la seguridad para volver a plantear sus hipótesis, abriendo nuevas posibilidades. Los escritos de Benjamin piden al lector que entre en un proceso de interpretación activo, en el que tiene que hacer mucho más que simplemente reconocer y asimilar ideas ya presentadas como resultado definitivo del proceso de pensar. Es decir, el acto de comprender estos textos es más complejo y exige más que la lectura de otros autores, que producen libros entendidos como obras acabadas.

\section{EI lenguaje como lo auténticamente humano}

Un primer ejemplo, que permite mostrar la manera de trabajar de Benjamin, es el conjunto de tesis sobre el lenguaje. ${ }^{2}$ Permítasenos jugar con la referencia a Heidegger, en ésta sección: el lenguaje es la casa del ser humano. Benjamin no compartía la concepción sobre el lenguaje de Heidegger, pero si parece que se vio obligado muy pronto a explicar (a explicarse a si mismo) cuál era su propia teoría del lenguaje. Sus conceptos sobre la historia y la sociedad contemporánea, así como su teoría de la experiencia requerían esa aclaración. El mismo Habermas considera que su importante teoría de la experiencia se basa en su concepción del lenguaje. (Habermas, 1984, p. 320)

Benjamin asigna una importancia fundamental al lenguaje. En su trabajo de 1916, Sobre el lenguaje en general y sobre el lenguaje de los hombres se ocupa del

\footnotetext{
2 Desde el principio (el ensayo Sobre el lenguaje en general y sobre el lenguaje humano data de 1916) Benjamin se interesó por los problemas de filosofía del lenguaje, sobre los que volvería a ocuparse en 1932 (Sobre la facultad mimética) y en 1935 (Problemas de sociología del lenguaje). En 1931, se describió a sí mismo como alguien que fue un filósofo del lenguaje hasta que en 1924 realizó un cambio completo, en el sentido de pasar a preocuparse prioritariamente por cuestiones de filosofía política y social. Posteriormente, desde comienzos de los años treinta, Benjamin realiza un análisis de la cultura burguesa, practicando en el terreno de la crítica cultural, algo no lejano a la crítica filosófica y política de G. Lukács, que constituye un nuevo pilar de la crítica de la ideología. (Tiedemann, 1988, p. 276) A finales de enero de 1939, recupera sus preocupaciones originales y aun realizará la recensión del libro de Richard Hönigswald sobre Filosofía y lenguaje. Por lo tanto, parece que el lenguaje es uno de los temas que estructura su obra, tal como defiende López de Lizaga (2005, pp. 15 y ss).
} 
ser lingüístico en sí mismo. ${ }^{3}$ Este es algo propio no sólo de la vida humana sino de toda la realidad. No existe cosa o acontecimiento, tanto en el mundo animado como en el inanimado que no participe de alguna manera del lenguaje, pues "es esencial a toda cosa comunicar su propio contenido espiritual" $(1999,89)$ a través de algún tipo de lengua. La realidad del lenguaje no sólo se relaciona con las diversas formas de la experiencia y la expresión humana, sino que se extiende a todo ámbito de la naturaleza animada o inanimada. Benjamin mantiene que el lenguaje no es una característica excusiva del ser humano, sino que se trata de una dimensión que se presente, de diversas maneras, en toda la realidad.

Sin embargo, el lenguaje de las cosas, no expresa nada, o nada distinto de sí mismo. Para Benjamin el lenguaje comunica la esencia espiritual, esta esencia se comunica en el lenguaje, y no por medio del lenguaje. En el mundo humano toda comunicación constituye una modalidad de lenguaje, está vinculada con el lenguaje, es, en definitiva, lenguaje. Así se puede hablar de un lenguaje de la música, de la escultura, de la ciencia. Pero el ser humano se comunica en y no a través de un lenguaje. Esta distinción se refiere a que el ser humano no es idéntico al ser lingüístico, y a que lo que es comunicable de una esencia o ser humano es sólo su ser lingüístico.

La lengua comunica, por consiguiente, el ser lingüístico de las cosas, comunica su ser ya que él mismo está incluido en el ser lingüístico, comunica los aspectos del ser que tienen carácter lingüístico y que, por lo tanto, son comunicables. $(1999,90)$ Lo que en un ser espiritual es comunicable es "aquello en lo cual se comunica" $(1999,91)$, es decir, la lengua misma; por lo cual se puede afirmar que "cada lengua se comunica a sí misma", (...) es lo inmediato de cada comunicación espiritual." $(1999,91)$ El ser espiritual se comunica como lengua, en forma lingüística.

La esencia lingüística de las cosas y del ser humano, en particular, es su lengua. El ser humano comunica lo que le hace humano - en la medida en que es comunicable- en su lengua, la cual se expresa en palabras y, por ello, dicha comunicación se efectúa nombrando las cosas. Afirma Benjamin, por consiguiente, que "la esencia lingüística del hombre es (...) nombrar las cosas.”(1999, 91) En este sentido, sólo el lenguaje de los seres humanos se basa en nombrar. El nombre, la capacidad de nombrar, es patrimonio de la lengua humana. Según Benjamin, en esto se funda la diferencia entre la lengua del ser humano y la de los animales o las cosas. Por otra parte, el ser humano, en su desarrollo como especie llega a ser plenamente humano

\footnotetext{
3 Se puede encontrar un comentario detallado de dicha obra en McNabb (2009, pp. 137-141). Gabriel Amengual (2008) identifica esta obra de Benjamin, como la más relevante para exponer su concepción sobre el lenguaje, junto a los comentarios sobre Kant. En la tesis de Luis Fernández Castañeda (1999) se considera el primer periodo de la obra de Walter Benjamin, y en especial su ensayo sobre el lenguaje de 1916, como núcleo de todo su pensamiento. Fernández analiza la idea del lenguaje como esencia espiritual del mundo y destaca, como se hace en nuestro propio artículo de otra manera, el concepto de traducción en dicha concepción.
} 
como ser que nombra. Según la interpretación de Habermas "el dar nombres es una especie de traducción de lo sin nombre al nombre, la traducción del lenguaje, menos perfecto, de la naturaleza al lenguaje humano." (1984, 318)

El nombre tiene la función "incomparablemente alta" de ser "la esencia más íntima de la lengua" $(1999,92) .{ }^{4}$ Desde el nombre, en el que halla su máxima expresión la totalidad del lenguaje: la del ser comunicante y la del ser comunicable, el ser humano -antes de ser miembro de una civilización concreta- habla el lenguaje puro, el lenguaje perfecto en universalidad e intensidad. 5 A diferencia de éste, la lengua de las cosas es imperfecta, dado que las mismas son mudas, pues les está negado el sonido (Rella 1992, p. 168), al menos su lenguaje carece de la complejidad sonora propia de las expresiones humanas. Es un lenguaje que carece de palabras. De todas maneras, las cosas de la naturaleza se comunican entre sí lingüísticamente y de un modo más o menos material, y el ser humano se comunica con ellas dándoles un nombre, a través del cual las conoce. Esta comunicación que el ser humano mantiene con las cosas, por la cual las conoce íntimamente en su ser lingüístico, implica una comunidad de carácter mágico con las mismas, comunidad mágica que es inmaterial, o sea, puramente espiritual. (Benjamin 1999, pp. 94-95; Rella 1992, p. 168)

En el Génesis, se pone en evidencia la "profunda y clara relación del acto de la creación con la lengua.” (Benjamin 1999, p. 95) La creación del mundo por Dios acontece en el verbo. Las cosas son creadas por el verbo, lo que es se puede interpretar como logos. Por ello, se puede afirmar que la lengua es "lo que crea y lo que realiza, es el verbo y el nombre" (1999, p. 96), pues la fuerza del lenguaje hace que se convierta en realidad lo que forma parte del logos.

La lengua puede ser concebida entonces como una característica que ha conseguido el ser humano y por la cual éste se ve elevado por sobre todas las cosas. Esto le ha permitido al ser humano conocer la lengua por medio de la cual se crea el mundo inteligible, la realidad, los seres. La lengua humana es sólo un reflejo del logos. El desarrollo de la creación, sin embargo, ha puesto en las cosas el germen del nombre que permite conocerlas, y al ser humano le ha sido asignada la tarea de desarrollar ese germen a través de la acción de nombrarlas. A través de la palabra, el ser humano da un nombre a las cosas, nombre que encierra el conocimiento de las mismas; pero puede hacer esto porque está unido a la lengua de las cosas. El ser

\footnotetext{
4 Adelantando una de nuestras hipótesis, se puede recordar cómo Derrida mantiene una posición similar cuando, en una de sus obras fundamentales (Márgenes de la filosofía), identifica al nombre como elemento clave de la metáfora como medio de conocimiento. (Derrida, 1989a, p. 275)

5 Retomando a Hamann, Benjamin señala que en ese estado, todo lo que el ser humano oye, ve y toca, todo aquello con lo cual está en contacto es palabra viviente, palabra emanada de Dios, quien es también palabra. El hombre adánico está en contacto directo con la palabra divina creadora de todas las cosas y por ello también tiene el conocimiento directo de ellas, por ello también la lengua paradisíaca es perfectamente conocedora.
} 
humano traduce el lenguaje de los seres a su propia lengua, traducción que no implica sólo transformar lo que es mudo en sonoro sino también convertir lo que no tiene nombre en algo que lo adquiere a partir de la acción denominadora humana, supone la "traducción de lo que no tiene nombre al nombre." (Benjamin 1999, p. 98) Esta traducción significa también, pasar de una lengua imperfecta a otra más perfecta, elevar a las cosas a un ser espiritual superior y hacer posible su conocimiento.

\section{El lector y las lecturas múltiples}

Con su teoría lingüística, Benjamin se aparta de la concepción tradicional de la lengua, para la que las palabras son resultado de convenciones instrumentales y socioculturales espontáneas, son signos arbitrarios que los seres humanos asignan casualmente a los entes. La concepción instrumental es superada por Benjamin en su intento de recuperar una perspectiva más rica de la lengua.

El conocimiento del verbo con el cual las cosas han sido creadas le permite al ser humano primigenio darles un nombre, aquél que connota y expresa el auténtico ser de las mismas, aunque quizá esa connotación no sea total, no responda totalmente a su esencia, a la cosa en sí, pues el nombre que da el ser humano a las cosas depende de la forma en que éstas se comunican con él, depende de lo que se pueda aprehender de ellas. No todos los seres humanos leen el mundo de la misma manera, la realidad es una obra abierta a múltiples lecturas, las cuales dependen de la capacidad de percibir, de recibir e interpretar la realidad.

El nombre es la resonancia patente en el alma humana de lo viviente o existente, es el eco audible de las cosas en el ser humano. En este sentido, la palabra humana tiene un aspecto receptivo, por el cual capta en mayor o menor medida la lengua de los seres a través de la cual "se irradia, sin sonido y en la muda magia de la naturaleza, la palabra divina." (Benjamin 1999, p. 97)

Una vez que el ser humano supera ésta fase, en la que hablaba una sola lengua, aparece una pluralidad de lenguas, en las cuales se diversifica, correlativamente, el conocimiento originario, que recibe, en consecuencia, multitud de traducciones. El ser humano posadánico abandona la contemplación de las cosas, se aparta de la íntima comunión con ellas que le permitía escuchar el nombre con que Dios las había creado, que le permitía escuchar su lenguaje sin palabras. Esto hace surgir la lengua como palabra humana, distante y diferente de la lengua nominal que el ser humano hablaba en el estado pre-civilizatorio. Este lenguaje de la "caída" actúa sólo como medio, como señal o signo que ya no expresa el nombre originario; éste es el lenguaje del hombre que pretende conocer el bien y el mal, conocimiento que no tiene nombre y que es pura "charla". (Rella 1999, p. 169) En términos de Benjamin: bien y mal son innombrables, sin nombre, fuera de la lengua nominal, que el ser humano abandona. (Benjamin 1999, p. 100) 
El pecado original, en este texto de Walter Benjamin, consiste en el acto de nacimiento de la palabra humana, la palabra de la abstracción y del juicio, hecho que ocurre debido al conocimiento del bien y del mal. Pero este conocimiento carece de la capacidad de conocimiento inmediato para todos los seres humanos; acarrea la ruina del espíritu lingüístico originario y se expresa en una lengua exteriormente comunicable, pero fragmentada en múltiples lenguajes.

Esta manera de presentar sus tesis sobre el lenguaje, tan cargada de metáforas teológicas, de alegorías bíblicas, convierte a Benjamin en un autor extraño a las tradiciones científicas de estudio del lenguaje, le aleja de precursores como C.S. Peirce (McNabb 2009, p. 137), pero también de sus contemporáneos. Sin embargo, no debe interpretarse como completamente anacrónica, su concepción del lenguaje se abrirá camino posteriormente en su peculiar materialismo histórico y resonará en los trabajos de Ernst Bloch y otros autores judíos que están en condiciones de entender su manera de expresarse6 (Mate 1999).

Como es evidente, Benjamin no puede ser considerado un precursor del giro lingüístico (Rorty 1990), pero si debe tenerse en cuenta como el lenguaje se convierte en uno de los temas más relevantes de su propuesta filosófica. Como dice Amengual: "La gran transformación y corrección al concepto de conocimiento orientado unilateralmente hacia la matemática y la mecánica sólo puede venir por la relación con el lenguaje (...). Incluso pronostica Benjamin que, más allá de la conciencia epistemológica que la filosofía puede aportar, la conciencia lingüística dará la supremacía a la filosofía." (2008, p. 38) Parece evidente que su predicción no se ha cumplido, pero la fuerza de su argumento a favor de la "conciencia lingüística" parece revivir en autores posteriores.

En cualquier caso, Benjamin no es un francotirador alejado de las tradiciones del pensamiento. Su participación en los debates que se están produciendo en su tiempo, así como su vinculación con otros autores, están bien documentadas. La característica diferencial de Benjamin es su manera de trabajar, como si nunca cerrara sus textos, como si nos diera a conocer borradores de trabajo.

Uno de los aspectos que más nos interesan de su breve ensayo de menos de veinte páginas Sobre el lenguaje en general y sobre el lenguaje de los hombres, es que fue redactado como un esquema para aclarar la propia concepción del lenguaje, este ensayo no se preparó para ser publicado y solo se dio a conocer a otros pensadores cercanos. La significación que este texto tuvo para Benjamin se demuestra

\footnotetext{
${ }^{6}$ El judaísmo de Benjamin, vinculado al pensamiento judío esotérico y mesiánico pero no a una práctica religiosa personal, así como su permanente amistad y debate con el teólogo Gershom Scholem, presentes en su obra, hacen que difícilmente pueda ser asimilada desde una perspectiva científica o desde concepciones marxistas. (Habermas 1984, pp. 321-322) Hay que recordar que Scholem mantiene una postura que va del mesianismo judío al anarquismo, influido por Bakunin, Kropotkin y Proudhon. Por su parte, Palmier (2006) hace una reivindicación del rigor de la obra de Benjamin, contra el tópico que lo considera un "rabino marxista" algo diletante.
} 
en la gran influencia sobre sus trabajos posteriores, en los dos citados antes y en $L a$ tarea del traductor que se analizará posteriormente.

\section{Obra abierta y diferencia. Benjamin y la deconstrucción del conocimiento convencional}

Cabe otro tratamiento, entre los muchos posibles, para a aclarar lo que planteamos sobre la manera de presentar sus tesis por parte de Benjamin. ${ }^{7}$ En otras publicaciones hemos analizado una parte de la filosofía de Benjamin, prestando atención a su trascendencia para el pensamiento y la práctica educativa, para profesionales interesados en esa temática (Ballester-Colom 2012). Pensamos que la mejor manera de proceder al principio de ese proyecto era seleccionar los escritos de las Obras Completas que tratan ese tema, analizar sus ideas claves y someterlas a una valoración a la luz de otras perspectivas que forman parte del debate contemporáneo sobre la educación. Sin embargo, este método lógico no podía dejar de tener en cuenta la característica ensayística y circunstancial de los escritos de Benjamin. Era necesario conocer diversos trabajos suyos que resultaron decisivos para trabajar con el tema, aunque no hablaran directamente de educación sino del lenguaje o la cultura. Pero tampoco bastaron estas obras y tuvimos que incorporar asimismo observaciones indispensables que aparecían en otras obras. Si el lector en este momento empieza a pensar que todo esto parece un jeroglífico que el investigador tiene que descifrar antes de poder iniciar su trabajo, es decir, antes de saber lo que dice el autor, ha acertado y ve el problema tal como es. Es hora de reconocer, como un principio hermenéutico general, que gran parte de la información para el estudio de muchos temas sólo la descubrirá alguien que haya leído las Obras Completas de Benjamin; alguien que haya reconocido, desde el principio, el hábito del autor de tratar los asuntos que más le interesan una y otra vez en todos sus escritos.

Otra manera de decir lo mismo es afirmar que la teoría y práctica del libro de Benjamin socavan los fundamentos mismos de una obra cerrada en cada uno de los libros. En repetidas ocasiones sus libros frustran las expectativas del lector de llegar a una conclusión definitiva, ese anhelo de alcanzar una respuesta absoluta. En vez de ser reflejos de un logos de referencia, capaz de ser captado y representado en palabras impresas en una página, quizás debamos pensar en las Obras Completas como un vasto fragmento complejo, en el cual se han insertado un tanto arbitrariamente títulos para crear la impresión de que las fronteras entre ellas son reales más bien que artificiales. Claro que exageramos al formularlo así, pero un poco de sobrecompensación puede ser necesaria, ya que nuestra tendencia tradicional nos

\footnotetext{
${ }^{7} \mathrm{La}$ forma de presentación de su obra no es ajena al contenido de la misma. No se trata de una forma circunstancial.
} 
hace creer que Benjamin escribía libros. Es posible, a fin de cuentas, que esta tendencia nos haya hecho entender mal una parte importante de la significación de sus escritos. ¿Nos hemos dejado engañar por la suposición previa -que nos parecía perfectamente razonable- de que Benjamin ha escrito libros entendidos como obras cerradas?

Tal vez se pueda afirmar que Benjamin es un deconstruccionista ${ }^{8}$ avant la lettre y la primera obra que construye y deshace es la suya. ${ }^{9}$ Si se puede aceptar que el método genealógico nietzscheano representa un precedente de la deconstrucción (Peretti 1989, p. 128), también se pueden encontrar estrategias de enfrentamiento al pensamiento occidental tradicional, así como a su manera de preparar y presentar la obra filosófica, en Benjamin que preceden las estrategias de la deconstrucción. Dos ejemplos pueden ayudar a entender el atrevimiento de aventurarse a pensar hasta qué punto Benjamin ha sido aprovechado posteriormente. En primer lugar, la concepción crítica con la tradición. Por parte de Benjamin, por ejemplo, la tradición es discontinuidad. Son necesarias las revoluciones y las experiencias destructivas para interrumpir la tradición. ¿Qué valor tiene entonces el gran patrimonio histórico y cultural, si la discontinuidad nos hace pobres y nos impide apropiarnos de él plenamente? La tradición cultural tiene para Benjamin un origen en el que no se puede pensar sin horror. Debe su misma existencia no sólo a la dedicación de quienes lo han creado, sino también a la esclavitud sin nombre de sus contemporáneos. No hay documento de cultura que no sea, al mismo tiempo, documento de barbarie; y tampoco es inmune a la barbarie la tradición cultural. En esta conocida crítica, Benjamin lleva hasta el límite el pensamiento hasta mostrar sus propios desajustes y contradicciones.

En segundo lugar, también a modo de ejemplo, se puede considerar que en Benjamin hay un tratamiento de la obra escrita, del libro, similar al que posteriormente desarrollará Derrida. Sin embargo, a pesar de la forma parecida en que tanto él como Derrida abordan el problema del libro, tenemos que ser prudentes. Es verdad que Derrida y sus discípulos analizan libros con el fin de demostrar la inutilidad de buscar una visión de la verdad completa o un conocimiento absoluto. Tienen una conciencia dramática de la enorme distancia que separa nuestras palabras de la realidad que éstas quieren describir (o descubrir). La preocupación típica de los

\footnotetext{
8 Se utiliza este término en lugar de "desconstruccionismo" por ser el más fiel a los textos de Derrida, aunque no siempre haya sido el término que ha dominado en las traducciones en castellano. Por ejemplo: Derrida (1989b).

9 Sabemos que Derrida lee atentamente la obra de Benjamin, hasta el punto de comentarla extensamente (por ejemplo: Derrida 2002) En su escrito Nombre de pila de Benjamin, Derrida (2002) ha revisado libremente la temprana filosofía del lenguaje benjaminiana. La influencia de Benjamin sobre la obra de Derrida es indiscutible, tal como se ha señalado, para el tema de la autoridad y la violencia, en la obra dirigida por A. Haverkamp (1994). De manera algo más general, también se puede considerar el trabajo de Company (1997).
} 
deconstruccionistas por una "diferencia" insalvable, que atraviesa la escritura, nutre un escepticismo radical con respecto a las pretensiones que han caracterizado a los libros (sobre todo en el mundo occidental).

La estrategia que Derrida emplea es muy conocida: muestra, con muchos detalles y con gran atención, cómo el sentido de un texto es aplazado o "diferido" infinitamente, y cómo existe una contradicción entre la "conclusión" buscada -entendida como respuesta definitiva- y la palabra escrita que inútilmente trató de exteriorizarla. Por cierto, después de haber examinado la naturaleza informal y literaria del discurso de Benjamin, es decir, su propia deconstrucción del libro, se podría sospechar que existe una afinidad espiritual con el escepticismo que anima la filosofía deconstruccionista. Pero aquí las apariencias engañan y un examen más cuidadoso del criterio que inspira el discurso benjaminiano requiere una conclusión diferente.

En primer lugar, si Benjamin mismo confiesa que no está satisfecho con los libros y la escritura, no es solamente porque comprende su limitación, sino porque se imagina un modo más eficaz para comunicar lo que quiere decir. Benjamin mantiene una conversación abierta a través de sus textos, artículos, intervenciones de radio. (Lenarduzzi 2009, p. 100) Esto explica por qué sus escritos son deliberadamente abiertos y fragmentarios; su propósito, en resumidas cuentas, ha sido abrir sus libros hacia el diálogo.

A lo largo de su trabajo, se puede comprobar fácilmente que Benjamin no se adapta bien al escepticismo de la deconstrucción. Su marxismo peculiar, su mesianismo residual, alientan la profunda esperanza que expresan sus obras en una posible solución para la crisis del mundo moderno. Nos referimos, por supuesto, a su confianza teórica en la razón histórica y en la razón política. (Mate 1991) Esta perspectiva y los esfuerzos de Benjamin por elaborarla en diversos textos importantes ${ }^{10}$, son completamente incompatibles con el escepticismo de los deconstruccionistas. Cuando el libro se aproxima al diálogo y puede privilegiar el habla por encima de la escritura, Benjamin cree que sigue legitimando los sueños humanos. Así, al mismo tiempo que Benjamin mantiene una deconstrucción del libro convencional, no cede a la tentación de negar la posibilidad de comunicar algo con sentido, con una trascendencia. El verdadero libro, el que logra transmitir el logos humano, es para él posible y puede encarnar una verdad más profunda que se revela en la sociedad y en la historia.

Se puede mantener esta interpretación de Benjamin contra el ataque de los deconstruccionistas. Se puede pensar que la teoría y práctica textual de Benjamin caen en una "metafísica de la presencia" tradicional y logocéntrica, de acuerdo con el concepto de Derrida. Cuando Derrida critica los presupuestos ocultos en las obras

10 Por ejemplo, en las conocidas Tesis sobre la filosofia de la historia, publicadas por primera vez en Los Angeles, en 1942, en un número especial de la revista que el Institut für Sozialforschung, ya editaba en Frankfurt antes del exilio a los Estados Unidos de Max Horkheimer. 
de Husserl, Saussure y Lévi-Strauss, cuando deconstruye, sin piedad y de manera brillante, los ideales que esos escritos pretenden realizar, critica también, por extensión, la "razón histórica", es decir, la versión de Benjamin del proyecto de modernidad ilustrada de los autores de la Escuela de Frankfurt. Además, el mismo mesianismo que Benjamin invocó para defender su visión del devenir social y humano sería un blanco fácil de la ironía de Derrida. El examen minucioso de la dinámica latente de la "diferencia" parece reducir a una ilusión toda declaración que pudiera afirmar la presencia de un logos en la palabra. Benjamin - diría Derrida- empieza de una manera correcta, pero desgraciadamente abandona pronto esta postura, como tantos otros, volviendo a la promesa tradicional que ha acompañado al libro a lo largo de la historia, entendiéndolo ahora como una aproximación al habla entre sujetos ilustrados.

\section{La traducción imposible: comprensión y expresión limitadas}

Existe en los escritos de Benjamin una sabiduría sutil y vigorosa que pone en duda la voluntad de subversión de los saberes, realizada por la tradición deconstruccionista ${ }^{11}$. Para comprender esta atrevida hipótesis, tenemos que examinar cómo Benjamin logra reformular todo el problema de forma nueva e insólita. Nuestro punto de partida para este proyecto puede ser un pequeño ensayo que él tituló $L a$ tarea del traductor, del año 192312. La revelación inesperada de una verdad, previamente oculta en un fenómeno aparentemente sin demasiada importancia, caracteriza uno más entre los breves, pero excelentes, ensayos del autor. Elegimos este trabajo porque el tema que trata es muy importante para la deconstrucción, Derrida dice que "la cuestión de la traducción y de la lengua de los conceptos" es esencial para su filosofía. 13 (Derrida 1989c, p. 86; Company 1997)

En este trabajo, Benjamin desarrolla su concepción del lenguaje humano como traducción del lenguaje del mundo, es decir, la concepción del conocimiento como traducción. Conocer es traducir interminablemente al lenguaje humano el sentido de la realidad (el lenguaje de las cosas y de los seres vivos). Toda la primera mitad del ensayo, insiste en las dificultades de la traducción, aunque también en su necesidad para la extensión a otras comunidades y para la supervivencia del texto a lo largo del tiempo. Benjamin sabe que las diferencias que separan a una lengua de otra son

\footnotetext{
11 Hasta en su estilo de escritura Benjamin escapa de la duda e incluye muchas afirmaciones apodícticas en su discurso; afirmaciones que replanteará si es necesario pero que no formula como proposiciones asertivas, que meramente aseveran que algo es o no, o como proposiciones problemáticas, que expresan únicamente la posibilidad que algo sea verdad.

12 Se trata del prólogo al libro titulado Charles Baudelaire, Tableaux parisiens (2010/1923).

13 El mismo Ortega y Gasset se preocupa, contemporáneamente a Benjamin, por el problema de la traducción entendida como paradigma de la dificultad de comunicación plena entre lenguas.
} 
grandes para permitir que uno acepte, sin más argumentos, la idea ingenua de que lo que se dice en una lengua puede decirse en otra. Sin embargo, plantea la relación profunda que existe entre las lenguas: “...las lenguas no son extrañas las unas a las otras, sino que ya a priori y con una completa independencia de los contactos históricos concretos, están emparentadas por aquello que pretenden decirnos." (2010, p. 12). No solo se traduce de una lengua a otra, también se traduce de un tiempo a otro, siguiendo la maduración del propio lenguaje a lo largo del tiempo: "las palabras escritas nunca terminan su maduración" (2010, p. 13).

En cualquier caso, las lenguas se han formado en escenarios diferentes y emergen de experiencias diferentes, existe una diferencia entre ellas que tiene que ser reconocida "entre aquello a lo cual nos referimos y la forma concreta en que lo hacemos" (2010, p. 14). Aunque la forma sea diferente, explica Benjamin, se puede pensar que lo que un alemán quiere decir con la palabra "brot" es la misma realidad que un francés llama "pain", se refieren a lo mismo. No puede olvidarse que esa traducción de contenidos solo incluye comunicación, se puede traducir todo aquello que es comunicación, pero "quedará intocable aquello mismo a lo que se dirige el trabajo del verdadero traductor. Eso que queda no es transferible, como la palabra literaria que es la propia del original, porque la relación que se establece entre el contenido y el lenguaje es completamente diferente en el original y en la traducción." (2010, p. 15)

Anteriormente, en los textos de Angelus Novus (1971)14, Benjamin ampliará sus tesis sobre las traducciones, defendiendo que las traducciones no son las que prestan un servicio a la obra original, sino que más bien deben a la obra su existencia, como parece evidente. Si la traducción es correcta, el original vuelve a la vida y consigue en ella una nueva exposición póstuma.

¿Cuál es la esperanza de la traducción completa? Es muy reducida: "En toda lengua como en sus productos existe, aparte de lo comunicable, algo que no es comunicable...”. (2010, p. 19) Benjamin salta más allá de su punto de partida (la traducción) y generaliza esta lección sobre la diferencia a las lenguas en general, a la comunicación entre lenguas. Se mantiene una diferencia substancial e infranqueable, solo cabe la esperanza para las obras más elevadas, las que expresan contenidos auténticamente universales: "Cuanto más elevada es una obra más traducible es, hasta en el roce más ligero que afecta a su sentido.” (2010, p. 21) Se consigue una traducción más profunda entre lenguas, como muestra Hölderlin al traducir a Sófocles o también en los textos sagrados. Benjamin pone muy difícil la comunicación, Hölderlin o los textos sagrados son una referencia difícil de emular y menos aun de superar.

\footnotetext{
14 En la tradición judía un ángel nuevo (Angelus Novus) es una criatura creada para cantar un cántico nuevo, recrea un cántico haciendo que sea un nuevo cántico.
} 
Como se ha dicho antes, existe una analogía evidente entre el acto de traducir una lengua a otra y el esfuerzo por traducir la realidad siempre elusiva a signos o palabras, al lenguaje humano, también se produce esa analogía en el mismo proceso de enseñanza-aprendizaje: siempre hay una diferencia que mantiene abierto el proyecto educativo y que acaba por constituirse en el horizonte del mismo proyecto.

Esta maniobra auténticamente filosófica y no sólo retórica, se convierte en una generalización, para que el ejemplo de la traducción pueda ser una especie de espejo que refleje una conclusión más amplia sobre el ser humano en Benjamin. La aceptación positiva de la naturaleza incompleta y siempre difícil de los proyectos de la humanidad. La imposibilidad de llevar a cabo completamente las aspiraciones que el ser humano se ha planteado no significa que no se haya alcanzado nada. Puede que un éxito total esté fuera de nuestro alcance: la verdad es que el ser humano es precisamente ese acto de esforzarse sin llegar plenamente a su meta, a una comunicación completa entre lenguas o a cualquier otro proyecto auténticamente humano. Pero creer que por esa razón el ser humano fracasa siempre y completamente, es un error injustificado. Es el error que algunos seguidores del deconstruccionismo cometen, como si hubiera un placer irresistible que se experimentara en el acto de huir de esa aceptación y de aniquilar toda posibilidad de sentido.

\section{Diferencia insalvable o voluntad de comunicación y proyecto}

En Benjamin hay una crítica constante del presente y del pasado-presente; pero también hay una clara voluntad de reconstrucción del presente. Podemos conjeturar que Benjamin habría simpatizado con algunos elementos críticos del ataque deconstruccionista, pero habría rechazado claramente sus consecuencias para el proyecto de transformación del mundo. Como dicen Gabriel Amengual et al., con "la propuesta de Benjamin (...) se abre realmente un futuro nuevo, un futuro realmente futuro, en el que no sea posible la marginación (la barbarie, la opresión) producida en la historia anterior. De esta manera la historia misma es concebida como interrupción, de modo que puede afirmarse que ahí empieza a pensarse la tradición de modo 'postradicional'." (2008, p. 24)

Esa lectura "postradicional" abre muchos de los caminos por los que transitará la filosofía posterior. La lengua (la palabra) será uno de sus temas fundamentales junto a la historia. La palabra -Benjamin lo sabe bien- no puede producir una presencia plena. Sin embargo, difiere de los deconstruccionistas no tanto en su apreciación de la diferencia -es uno de los primeros autores que entienden su importancia decisiva- cuanto en su manera de comprender el sentido más profundo de esa diferencia. Desafortunadamente, hay deconstruccionistas que rechazan esta posibilidad y transforman arbitrariamente una verdad incompleta en una mentira, argumentan- 
do a favor de una forma de escepticismo radical. Este tipo de deconstruccionista se muestra incapaz del utopismo, que los escritos propositivos de Benjamin expresan de una manera ejemplar. El deconstruccionismo difícilmente puede fundar un proyecto social o educativo, para seguir con el referente que hemos mantenido en secciones anteriores del artículo, aunque sí puede ayudar a entender sus limitaciones y complejidades.

No se nos presenta en los textos de Benjamin un mundo de una sola dimensión, donde, si uno no puede ser un dios, forzosamente tiene que ser un ente absurdo, es decir, donde las únicas alternativas son la presencia plena o la ausencia plena. Es evidente en qué sentido los escritos de Benjamin difieren tanto de los textos de los deconstruccionistas como de los textos convencionales de la tradición filosófica sistemática dominante. Benjamin, a su modo, meditaba sobre ideas que nos parecen vigentes hoy y las incorporaba a su pensamiento hace ochenta años. Sus conocidas Tesis sobre la filosofia de la historia, redactadas bajo el impacto del pacto germano-soviético, y que no fueron publicadas hasta después de la guerra, adquieren el valor de un testamento intelectual. En ellas insiste en su crítica fundamental de cualquier teoría del progreso y de la continuidad histórica, definiendo las tareas de un materialismo histórico que no se hunda en la "vulgaridad", perdiendo así cualquier posibilidad de contribuir a la transformación del mundo: debe alimentar un mesianismo que no se basa en la esperanza del radiante porvenir, sino en el desprecio de los tiempos actuales y la reactivación de lo mejor del pasado. Considerando la historia como una sucesión de derrotas que ven como los vencedores establecen permanentemente "el estado de excepción", Benjamin se proponía preservar, en el momento de máximo peligro, la posibilidad de salvación de la humanidad, reencontrando aquel pensamiento directamente metafisico, por no decir teológico del que creía haberse despedido definitivamente en 1935, con sus lecturas marxistas.

Para Löwy, el marxismo de Benjamin se identifica por su pesimismo productivo, "práctico, orientado plenamente al propósito de impedir, mediante todos los modos posibles, la llegada de lo peor" (Löwy 2007, p. 86). Si aceptamos la interpretación de Löwy, Benjamin, como idealista crítico, supo ver lo que estaba a punto de llegar, frente a la fe irresponsable de los marxistas convencidos de la necesidad del progreso, de la marcha indudable hacia la supuesta sociedad mejor. El idealismo crítico le permitió acertar en su pronóstico, aunque eso no le salvara la vida.

\section{Referencias bibliográficas}

Amengual, G. (2008): "Pérdida de la experiencia y ruptura de la tradición. La experiencia en el pensamiento de Walter Benjamin". En Amengual, Cabot y Vermal (eds.) Ruptura de la tradición. Madrid, Trotta, pp. 29-59. 
Amengual, G.; Cabot, M. y Vermal, J.L. (eds.) (2008): "Introducción". En Amengual, Cabot y Vermal (eds.) Ruptura de la tradición. Madrid, Trotta, pp. 9-27.

BAllester, L. y Colom, J.A. (2012): “Juventud y pedagogía (sobre la génesis del pensamiento de Walter Benjamin)", Teoría de la educación, 23 (1), pp. 71-106.

BenJAmin, W. (1999/1916): "Sobre el lenguaje en general y sobre el lenguaje de los hombres". En Ensayos escogidos. México, Coyoacán, pp. 89-104.

Benjamin, W. (1971/1921): Angelus Novus. Barcelona, La Gaya ciencia.

Benjamin, W. (2010/1923): Charles Baudelaire, "Tableaux parisiens". Obras, libro IV, vol. 1. 7-22. Madrid. Ádaba.

Company, S. (1997): Babel y la traducción o De Man y Derrida leyendo a Benjamin. Tropelías: Revista de teoría de la literatura y literatura comparada. 7-8, pp. 71-82

Derrida, J. (1989a): Márgenes de la filosofía. Madrid, Cátedra.

DERRIDA, J. (1989b): La desconstrucción en las fronteras de la filosofía. Barcelona, Paidós.

Derrida, J. (1989c): “Carta a un amigo japonés". Suplementos Anthropos, monográfico sobre Derrida. 13, pp. 86-89.

Derrida, J. (2002): Fuerza de ley. El "fundamento místico de la autoridad". Madrid, Tecnos.

Fernández Castañeda, L. (1999): Experiencia y lenguaje en Walter Benjamin. Madrid. Tesis doctoral UAM.

Habermas, J. (1984): Walter Benjamin. Perfiles filosófico-políticos. Madrid, Taurus, pp. 297-332.

Haverkamp, A. (ed.) (1994): Gewalt und Gerechtigkeit. Derrida-Benjamin. Frankfurt. Suhrkamp.

LeNARDUZZI, V. (2009): "Direcciones múltiples. Algunos recorridos por el pensamiento de Benjamin". Revista Anthropos, 225, pp. 100-111.

LóPEZ DE LizAGA, J.L. (2005): Walter Benjamin y los dos paradigmas de la teoría crítica. NEXO. Revista de Filosofía. 3, pp. 11-31.

LöwY, M. (2007): Walter Benjamin y el surrealismo: historia de un encantamiento revolucionario. Acta Poetica, 28 (1-2), pp. 73-93.

McNABB, D. (2009): "Benjamin y el lenguaje: reflexiones desde Charles S.Peirce", Revista Anthropos, 225, pp. 136-146.

Palmier, J.-M. (2006): Walter Benjamin: le chiffonier, l'ange et le Petit Bossu. Esthétique et politique chez Walter Benjamin. Klincksieck, París.

Peretti, C. de (1989): Jacques Derrida. Texto y deconstrucción. Barcelona, Anthropos.

Rella, F. (1992): El silencio y las palabras; el pensamiento en tiempo de crisis, Barcelona, Paidós. 
Reyes Mate, M. (1991): "Benjamin o el primado de la política sobre la historia". Isegoría, revista de filosofia moral y política. 4, pp. 49-73.

RorTy, R. (1990): El giro lingüistico. Barcelona, Paidós.

Tiedemann, R. (1988): "Dialectics at a Standstill: Approaches to the PassagenWerk". En G. Smith (ed.), On Walter Benjamin. Cambridge, MIT Press, pp. 260-291.

Lluís Ballester Brage

Facultad de Educación

Universitat de les IIles Balears

1luis.ballester@uib.es

Antoni J. Colom Cañellas

Facultad de Educación

Universitat de les IIles Balears

antoni.colom@uib.eu 